\title{
Histological study for the biological effect of Rosemary Rosmarinus officinalis L. essential oil on liver and kidney tissues
}
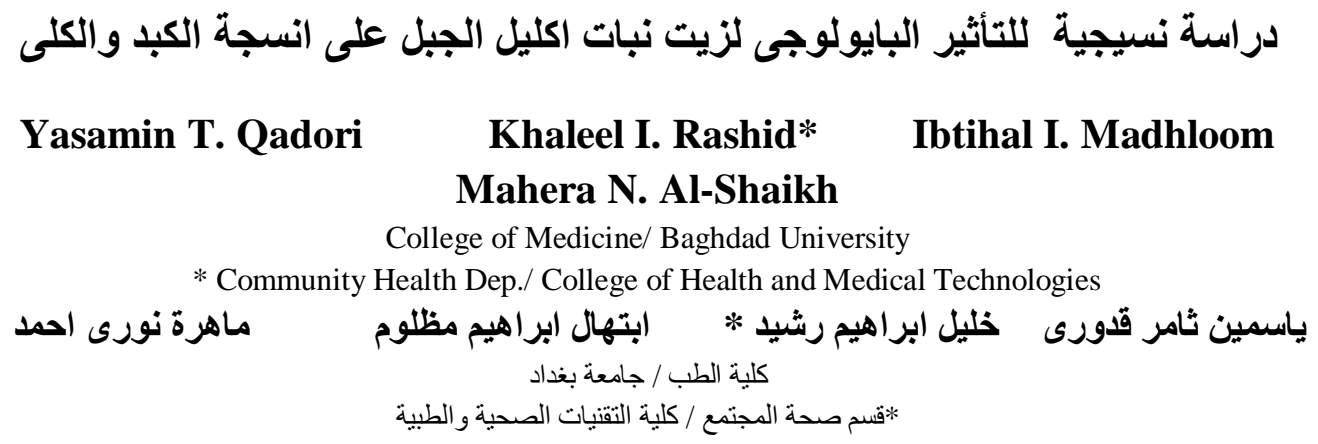

\section{Abstract}

Many herbs and plant extracts are added to the diet not only for their aromatic properties but they possess an important biological activity. The aim of the present investigation is to examine the biological activities (describes the beneficial or adverse effects of a drug and materials on living matter) of rosemary essential oil on liver and kidney tissues. The tissues treated with different doses of essential oil of rosemary $(100,200,300,400) \mathrm{ml}$. Histological examination of liver tissue treated with $400 \mathrm{ml}$ of rosemary revealed normal architecture with rate of stimulating cells more than the other concentrations, without dilated and congested of portal vein.

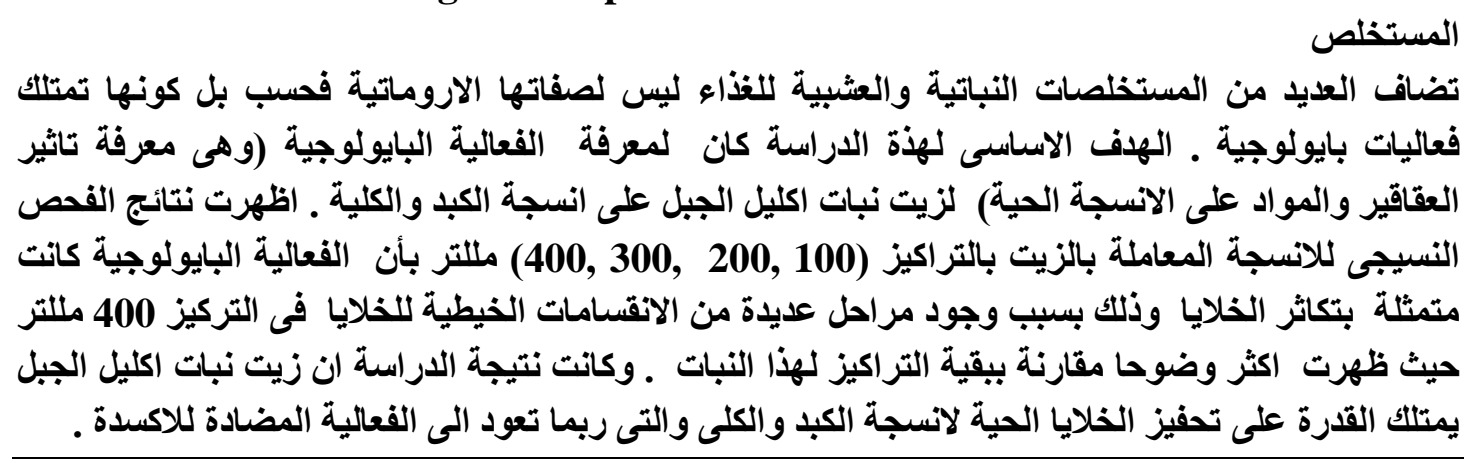

\section{Introdection}

Rosmarinus officinalis L. family Lamiaceae, is also known as rosemary. This herb is an evergreen shrub, with lovely aromatic linear leaves. Colored a dark shade of green above and white below, the leaves of the rosemary give off a beautiful fragrance, and with its small pale blue flowers, the plant is cultivated extensively in many kitchen gardens across America and elsewhere.

The essence of rosemary can be taken in the form of an infusion, a tea. The aromatic herb can also be used for a bath. Rosemary is often recommended especially for cases of low blood pressure. Both the volatile oil and the medication in the rosemary have been used as emmenagogues, which would be effective in stimulating menstrual flow and as abortifacients [1].

Almost all the physiological activity of the rosemary can be attributed to the volatile oil, which is present in the rosemary leaves in concentrations ranging from (1 - 2.5)\%. 
Alpha-pinene, camphene, verbenone, camphor, cineole, bronyl-acetate and borneol are all active compounds of the rosemary and determine the biological Properties of the essential oil and can act in synergic manner or regulate one another [2]. Chemical composition of rosemary essential oil can vary between regions and it depends mostly on climate, soil composition, plant organ, age and stage of vegetative cycle, all these compounds possess an adequate amount of antibacterial properties. Furthermore, the rosemary has stimulating properties, and this becomes more evident when the oil is applied locally. In addition, the leaves of rosemary contain a number of flavonoid pigments of which diosmin, is reported to decrease capillary fragility and permeability [3]. According to German health authorities, rosemary can prove to be effective for bringing in relief from indigestion. Rosemary can also be used as a supportive therapy for rheumatic disorders, and externally, rosemary is acknowledged for its efficacy and success in the treatment of circulatory problems. Though, the actual therapeutic effectiveness of rosemary is not yet known, and until today, no real systemic studies on the leaves of the aromatic herb have been conducted [4].

Extracts containing labiatic and carnosic acids have antioxidant or food preservative properties similar to those of butylated hydroxyanisole (BHA) and butylated hydroxytoluene (BHT), but it must always be remembered that large quantities of rosemary oil cannot be taken internally. The reason is that this may cause stomach irritation and disorders and can also irritate the kidneys and intestines [5].

The aim of the present investigation is to examine the biological activities (i.e. describes the beneficial or adverse effects of a drug or chemicals on living matter) of rosemary essential oil on liver and kidney tissues.

\section{Materials and Methods}

A total 10 adult albino male mice weighing (25-35) gm, were used in this study, they were isolated in a relatively controlled environmental temperature of about 25c, in the animal breeding center/ College of medicine/ Uuniversity of Baghdad. They were given food and free access to water. Mice were divided into 5 groups, 4 animals for each. Group I served as normal control mice injected with normal saline $0.9 \%$ only GroupII: the experimental groups were injected intraperitoneally with different doses of essential oil of rosemary(100, 200, 300, 400) ml. Animals were sacrificed after 3 hours by cervical dislocation, small pieces of tissues of liver, kidney, pancreas were removed for histological study by fixing in $10 \%$ formaldehyde, the specimens were dehydrated in ascending grades of ethanol, cleared with xylene and embedded in paraffin wax, sectioned to get $5 \mu \mathrm{m}$ sections, and stained with haematoxylin - eosin stain (H \& E).

\section{Results}

\section{In tissues treated with rosemary $100 \mathrm{ml}$}

The histological (heamatoxyline \&eosin stain) examination of liver tissue showed normal arcitucher of hepatocytes and sinusoids.

Kidney: Examination of the kidney revealed normal glomeruli with thin glomerular basement membranes, normal cellularity and patent capsular space surrounding by proximal and distal ducts except the enlargement of the blood vessels in this section Figure (1). 


\section{In tissues treated with rosemary $200 \mathrm{ml}$}

Liver: The histological examination appeared more or less normal with activated hepatocytes cells (cell in different stages of cell division); section also showed dilated and congested portal vein.

Light microscopy of the kidney sections showed an increase in the mesangial basement membrane, increase in the matrix of the glomeruli and hyalinization of the arterioles with the enlargement of some blood vessels in this section but it was less than in animals treated with $100 \mathrm{ml}$ of extract, in addition to that cell division appeared clear and more in number as compared with the tissues of animals treated with $100 \mathrm{ml}$ of rosemary.

Activated cells obviously clear showed in pancreatic tissue acini Figure (2).

\section{In tissues treated with rosemary $300 \mathrm{ml}$}

Liver: Nucleus of hepatocyte cells appeared large and activated much more obviously than in other concentrations of this herb, besides the portal vein appeared less congested as compared with other concentrations above.

Sections of kidney tissue revealed an increase in the mesangial basement membrane, increase in the matrix of the glomeruli and hyalinization of the arterioles and also showed activated duct cells Figure (3).

\section{In tissues treated with rosemary $400 \mathrm{ml}$}

\section{Liver:}

Examination of liver tissue treated with $400 \mathrm{ml}$ of rosemary revealed normal architecture of hepatocyte with stimulating (activated) cells more than the other concentrations, and without dilated and congested of portal vessels.

\section{Kidney}

Tissues showed an increase in the mesangial basement membrane, increase in the matrix of the glomeruli and hyalinization of the arterioles and obvious activated duct cells with enlargement of the blood vessels Figure (4).

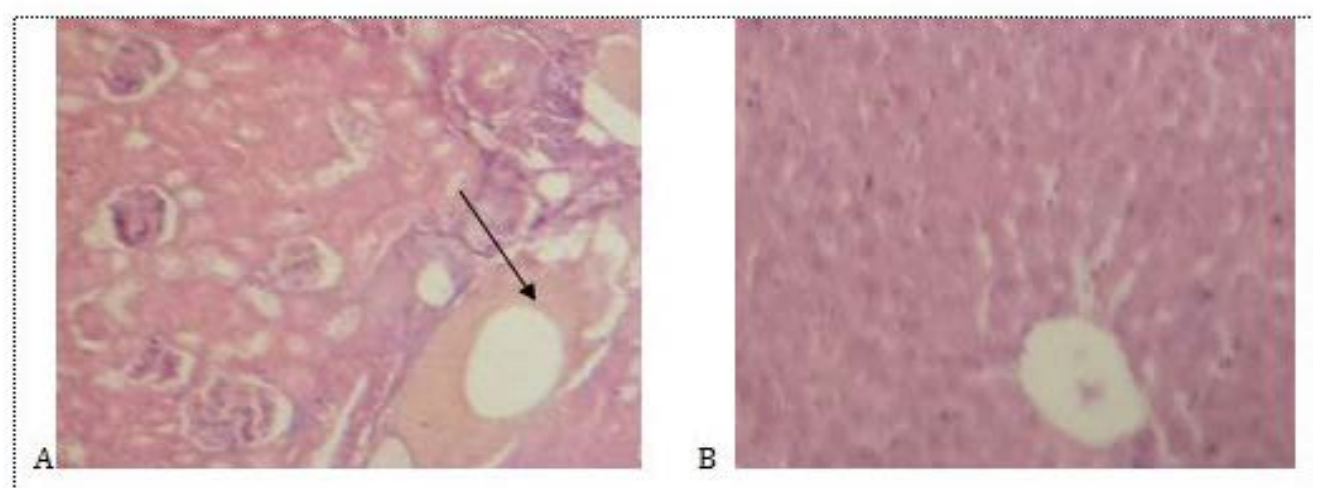

Fig. (1): In tissues treated with rosemary $(100 \mathrm{ml})$ : A- kidney tissue showed normal cellularity except the enlargement of the blood vessels in this section (arrow). B-Liver tissue showed normal arcitucher of hepatocytes and sinusoid. (H.P., stain H\&E) 

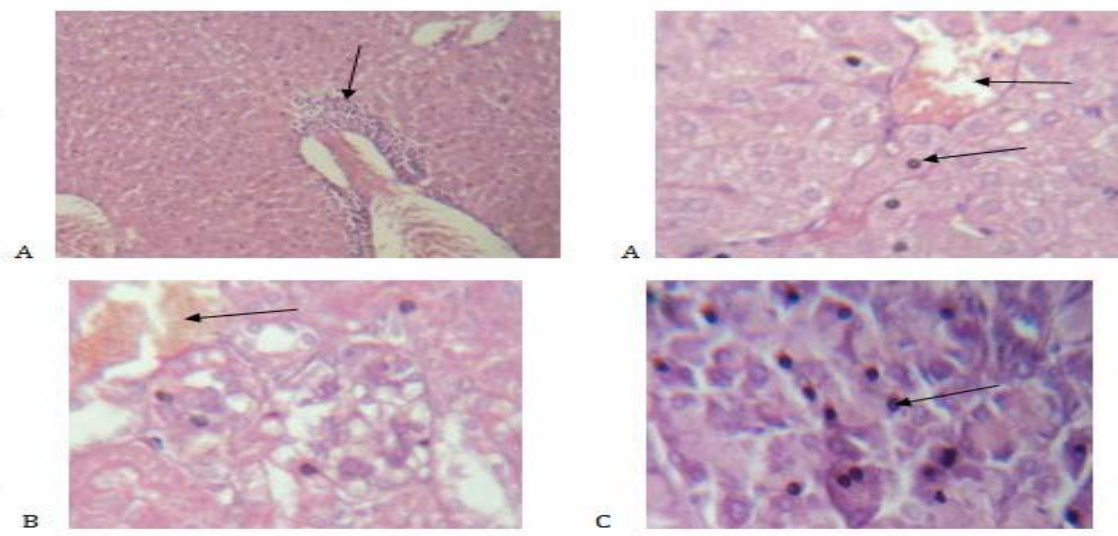

Fig. (2): In tissues treated with rosemary $(200 \mathrm{ml})$ : A- Tissue of liver showed active hepatocytes cells (cell division), section also showed dilate and congested portal vessel (arrow) (L.P. \&H. P.). $B$-Kidney tissue revealed hyalinization of the arterioles with the enlargement of blood vessels in this section (H.P.). C- Pancreatic tissue showed cells in different stages of cell division (arrow) (H.P.) (H\&E stain).
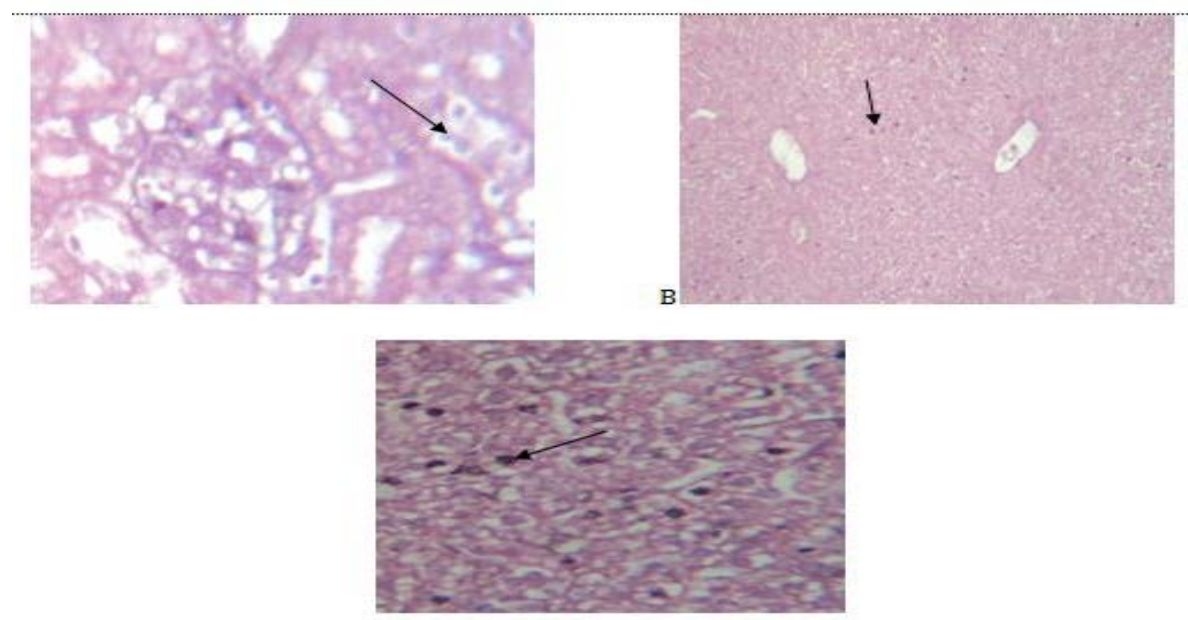

Fig. (3): In tissues treated with rosemary $(300 \mathrm{ml})$ : A- Sections of kidney tissue revealed an increase in the mesangial basement membrane, increase in the matrix of the glomeruli and hyalinization of the arterioles and also showed activated duct cells (arrow).B- Nucleus of hepatocyte cells appeared large and activated(arrow) much more obviously than in 100,200 ml, besides the congested portal vein appeared less as compared with other concentrations above(H\&E stain) .
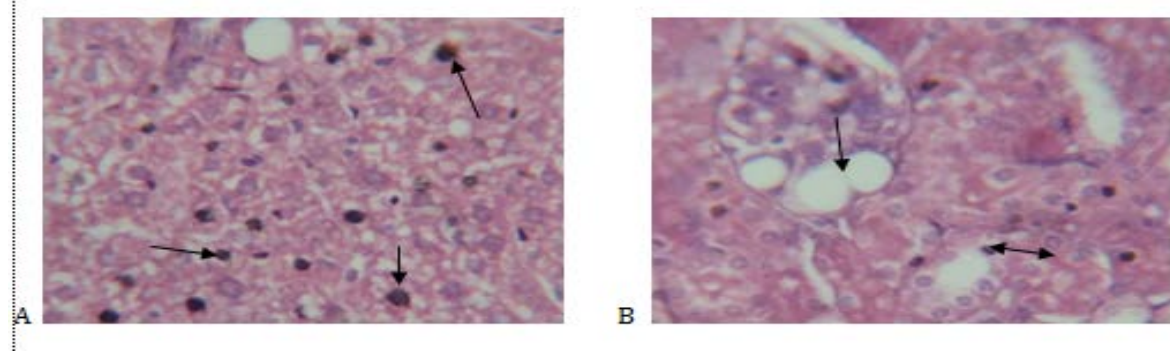

Fig. (4): In tissues treated with rosemary $(400 \mathrm{ml})$ : A- liver tissue revealed normal architecture of hepatocyte with stimulating cells more than the other concentrations (arrow), and without dilated and congested of portal vessels. B-Kidney tissue showed an increase in the mesangial basement membrane, increase in the matrix of the glomeruli and hyalinization of arterioles (arrow) (H\&E stain) and obvious activated duct cells $\longrightarrow$

\section{Discussion}

Rosemary in culinary or therapeutic doses is generally safe. A toxicity study of the plant on rats has shown hepatoprotective and antimutagenic activities [6], and this 
comes with the result of our study which shows that the presence of activated cells and in several stages of cell division indicated that the rosemary oil has the ability to stimulate the cells in liver and kidney tissues which it may be due to antioxidant activity of rosemary extract, and this agree with [7]. However, precaution is necessary for those displaying allergic reaction or are prone to epileptic seizures.

Rosemary essential oil may have epileptogenic properties, as a handful of case reports over the past century have linked its use with seizures in otherwise healthy adults or children [8]. Rosemary essential oil is potentially toxic if ingested. Large quantities of rosemary leaves can cause adverse reactions, such as coma, pasm, vomiting, and pulmonary edema (fluid in the lungs) that can be fatal. Avoid consuming large quantities of rosemary especially if pregnant or breastfeeding [9].

Free radicals/ reactive oxygen species are associated with many biological phenomena, such as inflammation, aging, and carcinogenesis. The antioxidant activity of polar extracts of rosemary is related to the content of polyphenols (PERP) compounds (i. e. carnosol, carnosic acid). Constituents in rosemary have shown variety of pharmacological activities for cancer chemoprevention and therapy in vitro and, in vivo models [10]. [11] reported that a single acute dose of PERP, given directly into the rumen highly susceptible to Lipoperoxidation enhanced the plasma total antioxidant status. The digestive processes of PERP in vivo arc beneficial by improving the biological effect of polymeric proanthocyanidins. It was found that addition of rosemary extract delayed the oxidation of lipid fraction of minced meat balls during storage in the freezer. The antioxidative effect was related to the concentration of the ethanol rosemary extract in the product [12]. Similar results were reported by [13] .In contrast to the above, other experiments have reported little or no antioxidant activity of rosemary [14] found that dietary supplementation with 500 or 1 $000 \mathrm{mg} / \mathrm{kg}$ of commercial rosemary extract had no effect on the lipid oxidative stability of eggs enriched with omega-3 fatty acids. Recent European research has shown rosemary interferes with the absorption of iron in the diet, which indicates it should not be used internally by persons with iron deficiency anemia [15].

\section{Conclusion}

Many investigations effects of rosemary essential oil in order to show that its constituents have important biological properties. Results of the relevant studies showed that there are biologically active compounds in rosemary essential oil exhibiting antioxidant properties especially with the concentration 400ml. Rosemary essential oil, however, does not enhance immune response and there are reports about its adverse effects on fertility. Essential oils, despite their wide use and being familiar to us as fragrances, constitute effective alternatives or complements to synthetic compounds produced by chemical industry without showing side effects.

\section{References}

1. Ray Sahelian, M.D. 2009. Encyclopedia of Rosemary. Internet.

2. Angioni, A., Barra, A., Cereti, E., Barile, D., Coïsson, JD., Arlorio, M., Dessi, S., Coroneo, V., Cabras, P. 2004. Chemical composition, plant genetic differences, antimicrobial and antifungal activity investigation of the essential oil of Rosmarinus officinalis L. J Agric Food Chem. Jun 2;52(11):3530-5. 
3. Faixov6, Z.r., Faix, S., 2008. biological effects of rosemary (Rosmarinus officinalis L.) Essential oil (A Review). Folia Veterinaria. 5, 2, 3-4: 135-1392.

4. Prabuseenivasan, S., Jayakumar, M., Ignacimuthu, S. 2006. In vitro antibacterial activity of some plant essential oils. BMC Complement A. ltern. Med. 6, 39- 45.

5. Saito, Y., Shiga, A., Yoshida, Y., Furuhashi, T., Fujita, Y., Niki, E. 2004. Effect of noval gaseous antioxidative system containing rosemary extract on the oxidation induced by nitrogen dioxide and ultraviolet radiation. Biosci Biotechnol Biochem. Apr. 68(4):781-6.

6. Fahim, F.A., Esmat Fawzia, A., Fadel, AY. Hassan, HM.1999. Allied studies on the effect of Rosmarinus officinalis L. on experimental hepatotoxicity and mutagenesis. International Journal of Food Sciences and Nutrition. 50 (6): 413-427. doi: 10.1080/096374899100987. PMID 10719582.

7. Bao, Ting Zhu, Daneil, P., Loder, May Xiaoxin Cai, Chi-Tang Ho, Mou-Tuan Huang and Allan, H. Conny. 1998. Dietary administration of an extract from rosemary leaves enhances the liver microsomal metabolism of endogenous estrogenes and decreases their uterotropic action in CD-1 mice. Carcinogenesis vol.19 no.10 pp. 1821-1827.

8. Burkhard, P. R., et al. 1999. Plant-induced seizures: reappearance of an old problem. Journal of Neurology 246 (8): 667-670. doi: 10.1007/s004150050429. PMID 10460442.

9. Article at HealthComm, 2010 http://www.healthcomm.com/resources/imc/OneMedicineCons/ConsHerbs/Rosemarych.html.

10. Shabtay, A., Sharabani, H., Barvish 2, Kafta, M., Amichay, D., Levy, J., Sharoni, Y., Uskokovic, M R., Studzinski, G P., Danilenko, M. 2008. Synergistiac ntileukemic Activity, f, carnosica cid-richr osemarye xtracta nd the 19-nor Geminiv itamin D analoguein a mousem odelo f systemic. acutem yeloidl eukemia Oncology. 7,5 , 203214.

11. Gladine, C., Rock, 8, Morand, C., Bauchart, D., Durand, D. 2007. Bioavailability and antioxidant capacity of plant extracts rich in polyphenols, given as a single acute Dose in sheep made highly susceptible to lipoperoxidation . Br. J. Nutr. 18. 691-701.

12. Karpinska, M., Borowski, J., Danowska-Oziewicz, M. 2000. Antioxidative activity of rosemary extract in lipid fraction of minced meat balls during storage in a freezer. Nahrung. 44, 38-41.

13. Lopez-BoteC, J., Gray, J.L., Gomaa, E.A., Flegal, C.J. 1998. Effect of dietary administration of oil extracts from rosemary and sage on lipid oxidation in broiler meat. Br. Poult. Scrl. 39: 235-240.

14. Galobart, J., Barroeta, A.C., Baucells, M.D., Codony, R., Ternes, W. 2001. Elfect of dietary supplementation with rosemarye xtract and alpha-tocopheryl acetate on lipid peroxidation in eggs enriched with omega 3-fatty acids. Poult. Sci. 80, 460-467.

15. Pelletier, Kenneth R., MD. 2002. "Western Herbal Medicine: Nature's Green Pharmacy." Chapter 6: The Best Alternative Medicine. New York: Simon and Schuster. 